\title{
Injury and illness surveillance at local Special Olympic games
}

\author{
D.P. McCormick MD, V.N. Niebuhr Ph D and W.L. Risser MD \\ Department of Paediatrics, University of Texas
}

\begin{abstract}
The purposes of this study were to: determine the incidence of injury and illness among Special Olympic athletes at local competitions; assess the relative risk of medical problems among Down's syndrome athletes; and compare the relative risk of sports injury incurred by athletes participating in various Special Olympic events.

Health stations were set up at all sports venues and injury/illness surveillance records were kept for all injury/illness encounters during a 3-day competition for 777 Special Olympic athletes. A total of $3.5 \%$ of the athletes required injury/illness care during the games. Down's syndrome athletes were 3.2 times as likely to encounter a medical problem. Track and field events provided the least activity time and the most injuries.

These data suggest that Special Olympic games at the local level are safe and that planners should prepare to treat more illnesses than injuries at such competitions.
\end{abstract}

Keywords: Athletic injuries, sports, sports medicine, mental retardation, physical fitness, Down's syndrome

Special Olympics is a sports programme for retarded athletes, both adults and children who have attained the age of at least 7 years. The programme has been in existence for over 20 years, and now is available in all $\mathbf{5 0}$ of the United States and in $\mathbf{5 0}$ foreign countries. Numerous sports are played by Special Olympics athletes including track and field, equestrian events, soccer, swimming and gymnastics. In the United States, Special Olympic sports are organized by State, and within each State the competitions are organized into local areas. National games are held annually, and international winter and summer games are held once every 4 years. An estimated two million athletes participate in Special Olympics worldwide.

Health care systems for Special Olympic games are necessary. In the United States, at the Special Olympic International Games in Baton Rouge (1983), and again at the Special Olympic International Games in South Bend (1987), extensive health care systems were set up to care for injured and ill athletes.

Address for correspondence: David P. McCormick MD, 301 University Boulevard, The University of Texas Medical Branch, Department of Pediatrics, Child Health Center-C19, Galveston, Texas 77550, USA

(C) 1990 Butterworth-Heinemann Ltd 0306-3674/90/040221-04
However, little is known about the health needs of Special Olympic athletes at the local level.

Injury and illness surveillance at Special Olympic games is important because there is a need to document safe participation and to identify sporting activities which may result in injury to the retarded athlete. It is also important to identify any factors which might predispose a Special Olympics athlete to injury or illness. For instance, large numbers of Down's syndrome athletes participate in Special Olympics. Does Down's syndrome predispose to problems during athletic competition? Furthermore, can some sports be identified which are safer than others? These questions were addressed in a study of injuries and illnesses at a local Special Olympic competition.

\section{Methods}

\section{Surveillance record}

The injury/illness surveillance record was similar to records developed for use by the National Athletic Injury Report System developed at Pennsylvania State University ${ }^{1}$, but adapted for use with handicapped athletes. Primary categories listed on the record were demographic data, cause of injury or illness, injury diagnosis, body part injured, severity, source of diagnosis, principal management, predisposing factors, sporting event when injured, and physician's note. Predisposing factors for handicapped athletes were identified by studying results of previous large scale data collections for Special Olympic competitions and communicating with members of the medical advisory committee for Special Olympics International. The surveillance record was organized to enable data analysis by entry of code numbers for each category onto a database computer file. The surveillance record and study methods were reviewed and approved by the Institutional Review Board of the University of Texas Medical Branch at Galveston.

\section{Data collection}

A paediatrician, paediatric resident trainee, or registered nurse staffed first aid stations at all five venues (soccer, equestrian, track/field, swimming/diving, 
gymnastics) during the 3 days of the games. The principal investigator was on call for all illnesses or injuries incurred by the athletes during the entire period of the competitions. Copies of the athletes' annual physical examination forms were on file at each venue. When athletes reported to the first aid stations, the athlete's preparticipation physical examination record was reviewed, and first aid and illness care was rendered by the physicians. Injury/ illness surveillance records were completed for all encounters. After the games, coaches were contacted by telephone to obtain information on injured or ill athletes who did not report to the first aid stations during the time of the games. A sports injury was defined as an injury resulting directly from participation in a sports event.

\section{Activity times}

With a stopwatch, research assistants recorded measured activity times (MATS), the length of time each athlete actually took part in practice or competition. Total MATS for each sport were calculated by summing MATS for each participant.

\section{Medical record review}

Preparticipation physical examination records were reviewed and the number of Down's syndrome athletes participating in the games was counted. The number of athletes participating in the games was counted. The number of athletes participating in each event, and the total number of athletes participating in the games were obtained from logs kept by Special Olympic scorekeepers.

\section{Data analysis}

The standard method was used for calculating relative risk ${ }^{2}$. For each category, the number of athletes experiencing injury or illness was divided by the number of athletes with no injury or illness.

Injury rates were calculated according to the method of Silverwood ${ }^{3}$. In order for these data to be compared with data from previous studies, it was necessary to calculate a sports injury rate utilizing event time (Method I). The denominator in this rate calculation is determined by multiplying the number of participants in an event by the total duration of the event in hours. This rate (rate $)_{1}$ ) equals the number of sports injuries divided by the number of participanthours of exposure to the event.

The relative safety of events can be accurately compared only if the actual activity time is measured for each participant, since many athletes are inactive during some sporting events. For instance, track and field events may run for 3 hours, but an athlete may only be sprinting for 45 seconds during the 3 hours. The denominator in this injury. rate calculation (Method II) is determined by summing the measured activity times for all athletes participating in the event. The injury rate $\left(\right.$ rate $_{2}$ ) equals the number of sports injuries divided by the number of participanthours of measured activity time.

\section{Results}

\section{Subjects}

A total of 541 Special Olympic athletes from 19 teams participated in track and field, soccer, gymnastics, and equestrian activities in the spring games in Galveston, Texas. Games ran for 32 hours (Friday 1.00 p.m. to Saturday 9.00 p.m.). At a second competition 2 months later, 419 athletes from 24 teams participated in swimming and diving. Swimming and diving competitions ran for 10 hours (Saturday 8.00 a.m. to 6.00 p.m.). A total of 777 athletes participated in both sessions; 238 athletes from 19 teams participated in swimming and diving only. A total of 346 athletes from 14 teams participated in track and field only, 12 athletes participated in equestrian only, 181 athletes from five teams participated in both swimming/diving and track/field. A total of 162 athletes (20.8\%) had Down's syndrome.

\section{Injury/illness encounters}

Of the 777 athletes, 27 (3.5\%) injury/illness encounters were reported. Twelve (44\%) of these 27 athletes had Down's syndrome. The largest number of visits (12) to the first aid stations was for management of eye problems. Particularly common was chemical conjunctivitis caused by irritation from sun screen applied to the face.

Table 1 summarizes the relative risk of injury/illness for Down's syndrome athletes versus other retarded athletes. The risk for Down's syndrome athletes was 0.080 and for others was 0.025 . Down's syndrome athletes at these games had a relative risk of injury or illness 3.20 times greater than the other athletes.

\section{Sports injury rates}

Three injuries occurred during track and field events (two leg muscle strains and one patellar subluxation). The fourth sports injury occurred during diving competition when a diver struck her hand on the diving board while performing a reverse dive.

Table 2 compares injury rates using the two methods. The results are summarized for the five venues: equestrian events, gymnastics, soccer, swimming/diving, and track/field. The Method I injury rate calculated on event time is 0.0004 injuries per participant-hour. The Method II injury rate calculated

Table 1. Relative risk of injury/illness for Down's syndrome athletes at Special Olympic games

Down's syndrome Other

\begin{tabular}{lrr}
\hline $\begin{array}{l}\text { Number of participants } \\
\begin{array}{l}\text { Number experiencing injury or } \\
\text { illness }\end{array}\end{array}$ & 162 & 615 \\
$\begin{array}{l}\text { Number with no injury or illness } \\
\text { reported }\end{array}$ & 12 & 15 \\
$\begin{array}{l}\text { Risk } \\
\text { Relative risk }\end{array}$ & 150 & 600 \\
\hline
\end{tabular}


Injury and illness surveillance at local Special Olympic Games: D.P. McCormick et al.

Table 2. Comparison of two methods for calculating sports injury rates among Special Olympic athletes when event times and measured activity times are known

\section{Method 1}

\begin{tabular}{lc}
\hline Event & $\begin{array}{c}\text { Event time } \\
\text { (participant-hours) }\end{array}$ \\
\hline Equestrian & 104 \\
Gymnastics & 152 \\
Soccer & 22 \\
Swimming/diving & 2890 \\
Track/field & $\underline{6773}$ \\
Total & 9941 \\
\hline
\end{tabular}

Rate $_{1}=(4$ injuries $) \div(9941$ participant-hours $)=0.0004$ injuries per participant-hour

\section{Method 2}

\begin{tabular}{lcc}
\hline Event & $\begin{array}{c}\text { Number of } \\
\text { athletes }\end{array}$ & $\begin{array}{c}\text { MATS (\%)* } \\
\text { (hours) }\end{array}$ \\
\hline Equestrian & 26 & $13.0(22.3 \%)$ \\
Gymnastics & 32 & $5.1(9.1 \%)$ \\
Soccer & 22 & $16.1(28.8 \%)$ \\
Swimming/diving & 419 & $16.2(28.9 \%)$ \\
Track/field & 527 & $5.5(9.9 \%)$ \\
Total & & 55.9 \\
\hline
\end{tabular}

Rate $_{2}=(4$ injuries $) \div(55.9$ participant-hours $)=0.07$ injuries per participant-hour

*Sum of measured activity times, MATS, for all athletes participating in each sport

on measured activity time (MAT) per athlete is 0.07 sports injuries per participant-hour.

Table 3 lists the average activity times per participant for each event. Soccer provided the most activity time per participant and track/field the least. However, track/field participation accounted for more sports injuries than any other event.

\section{Discussion}

Previous research has indicated that nonhandicapped adult athletes sustain injuries at rates (per 1000 participant-hours) of 0.03 for swimming ${ }^{4}$, 0.22 for sailboarding $5,2.9$ for badminton ${ }^{6}, 2.8$ for aerobic dancing ${ }^{7}$, and 3.65 for soccer ${ }^{4}$. Higher rates have been reported for contact or collision sports such as football (4.1), ice hockey (4.7), and handball $(8.3)^{8,9}$. Based on event time, we calculate a sports injury rate for Special Olympic athletes of 0.4 per 1000 participant-hours. This places Special Olympic events in the lower range of injury risk as compared with other sports activities.

Few prior studies have reported injury rates based on measured activity times. Most researchers have reported sports injuries as the number of injuries per participant-year, or the number of injured athletes reporting to a clinic or emergency room over a given time period. True risks of the various sports can be compared only if actual exposure times are known.
Table 3. Average activity time per athlete and injuries incurred in each sport

Event

Average activity time Number of injuries (minutes)

Equestrian

Gymnastics

Swimming/diving

Track/field

30.0
9.5
43.6
2.3
0.6

Comparison of MATS between events reveal differences in the amount of actual participant involvement in various sports. Soccer provided 73 times as much activity time per athlete as track and field yet resulted in no injuries. Prior studies of non-handicapped groups are in agreement with our data suggesting that track events may be more hazardous ${ }^{10-12}$. Since exercise and fitness are goals of the Special Olympics, coaches and programme leaders might take a cue from this data which indicates higher levels of activity and lower injury rates for soccer.

The majority of medical problems encountered by the Special Olympic athletes at competitions and games are illness-related and not injury-related. This has been observed on a large scale at national and international Special Olympic competitions. Medical coverage at games should include practitioners with expertise in primary care. First aid stations should be equipped to handle the treatment of seizures, lacerations, abrasions, contusions, splinters, sunburen, heat exhaustion, eye injuries, sprains, and strains. Access to a hospital, communications between caregivers at the sports venues, and continuous on-site coverage is recommended. In hot climates, Special Olympic games should be held during the coolest times of day and year. Plenty of shade and water should be provided, and coaches should constantly remind their teams to drink if the weather is hot and humid.

Our Special Olympic injury/illness record is available for use at local, regional and national games. When combined with the athletes' health forms, the record provides a data system for monitoring the safety of Special Olympic games. Computer-assisted data analysis is practical for large games such as the 1987 summer games at South Bend, Indiana, at which more than 4000 athletes participated.

Organized athletic programmes should promote illness/injury reporting to assure safe participation and to identify problem areas that need to be improved. Planners need to be aware that illnesses and injuries do occur and that health services should be provided as a part of the comprehensive approach to organizing sports for the handicapped.

\section{References}

1 Clark, K.S. NAIRS I, Recorder's Handbook, 1975-1976 Pennsylvania State University, University Park, PA, 1975 
Injury and illness surveillance at local Special Olympic Games: D.P. McCormick et al.

2 Gordis, L. 1988 Estimating risk and inferring casuality in epidemiology Epidemiology and Health Risk Assessment (Ed) Gordis, L. Oxford U. Press, Oxford, 1988

3 Silverwood, G.P. Accident investigation and reporting Sports Safety (Ed) Yost, C.P. American Association for Health, Physical Education, and Recreation, Washington, 1970

4 Weightman, D. and Browne, R.C. Injuries in eleven selected sports $\mathrm{Br}$ J Sports Med 1981, 9, 136-141

5 McCormick, D.P. and Davis, A.L. A study of injuries in sailboard enthusiasts Br J Sports Med 1988, 22(3), 95-97

6 Jorgensen, U. and Winge, S. Epidemiology of badminton injuries Int J Sports Med 1987, 8, 379-382

7 Garrick, J.G., Gillien, D.M. and Whiteside, P. The epidemiolo- gy of aerobic dance injuries Am J Sports Med 1986, 14, 67-72

8 Jorgensen, U. The epidemiology of injuries in typical Scandinavian team sports $\mathrm{Br}$ J Sports Med 1984, 18, 59-63

9 Jorgensen, U. and Schmidt-Olsen, S. The epidemiology of injuries in ice hockey $\mathrm{Br}$ I Sports Med 1986, 20, 7-9

10 Garrick, J.G. and Requa, R.K. Injuries in high school sports Pediatrics 1978, 61, 465-469

11 Requa, R.K. and Garrick, J.G. Injuries in interscholastic track and field The Physician and Sports Medicine 1981, 9, 42-49

12 Backx, F.J.G., Erich, W.B.M., Kemper, A.B.A. and Verbeek, A.L.M. Sports injuries in school-aged children. An epidemiologic study Am J Sports Med 1989, 17, 234-240

\section{तe" \\ Bodystat \\ CHANGING ATTITUDES TO HEALTH}

Bodystat Lid.

Havelock House

16 Mount Havelock

\section{Douglas}

Isle of Man

Tel: (0624)623111

Fax: (0624)625691

\section{Bodystat 500 The tut about booy composition}

Quality of life, that often quoted essential of living in the twentieth century, is inexorably tied to good health.

This may sound like truism, but is despite publicity a sadly neglected fact. Health is often only considered in its counterpoint - sickness - and only given due regard when it breaks down.

Unfortunately the commonest causes of illness in the western world are all self inflicted, Smoking - Alcoholism - Obesity, all three are related and deserve direct intervention if that desired quality of life is to be fulfilled.

Until recently weight management has been confined to the

"Eat less, use more will power" dustbin. But now there is a

genuine alternative. Bodystat 500 uses proven scientific methods to assessing total body fat and its corresponding constitution ratios, combining with full analysis to produce accurate and identifiable weight loss programmes.

Bodystat 500 uses the painless measurement of bio-impedance to compute in seconds which had previously taken hours with extensive equipment to achieve. Unlike methods such as skinfold thickness measurement, it is operator independent and reproducible. Unlike total immersion it is simple and acceptable and, unlike radio-isotope studies, the equipment cost is not prohibitive.

Bodystat $\mathbf{5 0 0}$ with its simple four connections to hand and foot requires no special operator skills, and in addition to body fat, Bodystat 500 also provides a reading of body water.

BODYSTAT 500 comes complete with a full software package (PC compatible) which not only interprets the measurements made, but can use them to provide a planned programme of weight loss through calorie reduction and exercise. Equally given targets can be aimed for and a valid end point achieved.

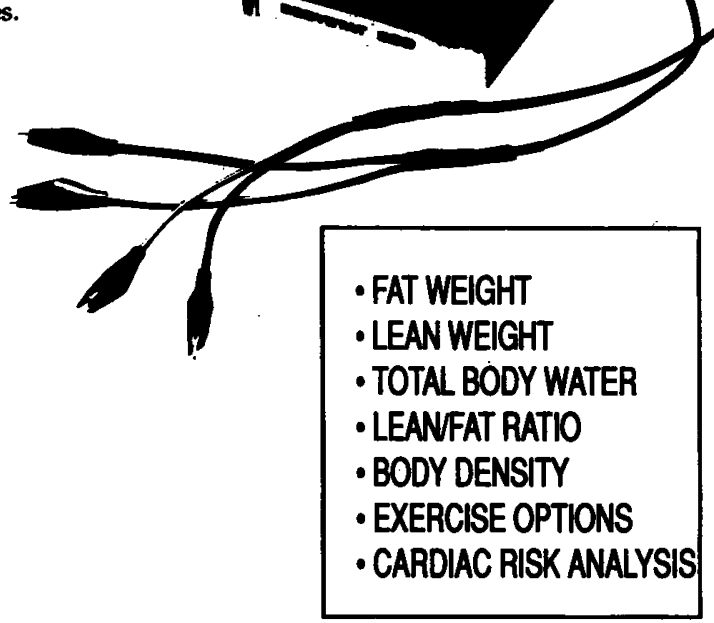

